\title{
REVIEW
}

\section{The development of Origanum vulgare $L$. into nanoparticles in dosage forms}

\author{
Lutfi Chabib ${ }^{1,2}$, Arman Suryani ${ }^{2}$, Muhammad Iqbal Pangestu ${ }^{2}$, Adnan Muhammad Uno J Hidayat ${ }^{2}$, A.M. \\ Bagas Trianloka ${ }^{2}$, \\ ${ }^{1}$ Department of Pharmacy, Islamic University of Indonesia, Yogyakarta 55584, Indonesia \\ 2 Professional Pharmacy Education Program, Islamic University of Indonesia, Yogyakarta 55584, Indonesia
}

\author{
Keywords \\ Aromatic plant \\ Nanotechnology \\ Origanum vulgare $L$.

\section{Correspondence} \\ Lutfi Chabib \\ Professional Pharmacy Education Program \\ Islamic University of Indonesia \\ Yogyakarta 55584 \\ Indonesia \\ lutfi.chabib@uii.ac.id
}

\begin{abstract}
Introduction: Origanum vulagre $L$. is known for its abundant essential oil content with monoterpene and sesquiterpene derivatives. Aims: This research aims to gather comprehensive information about oregano and its potential to be developed into a nanotechnology drug delivery system. Methods: Literary studies were conducted using data obtained by searching through online literature sources. Results: Oregano is reported to contain active phytochemicals like esitronellol. In modern scientific literature, its extracts have been reported to have antidiabetic, analgesic, antiinflammatory, anticancer and other potential properties. Further research needs to be done to ascertain the safety and therapeutic effect of this plant. The development of oregano's essential oil into nanoparticles in dosage forms can increase its solubility, stability, and pharmacological effects.
\end{abstract}

\section{Introduction}

Aromatic plants are considered to be very attractive plants because of their taste and pharmacological effects. Most of these aromatic species belong to the family Lamiaceae, whose distribution centre is located in the Mediterranean region. Within this family, oregano (Origanum vulgare subsp. Vulgare) is one of the most widely used species (De Falco et al., 2013). It is an important culinary herb in world trade and has been widely distributed in China and several Central Asian countries (Gong et al., 2014).

In the last few decades, oregano (Origanum vulgare L.) has become a valuable natural source that is used for maintaining human health. Oregano, in the form of dry herbs and essential oils, has been used in medicine for a long period of time and is one of the most widely used natural therapies (Gong et al., 2014).

Oregano is widely used as a traditional medicine to treat various diseases such as fever, jaundice, seizures, indigestion, and menstrual problems (Gong et al., 2014). Other benefits include preventing infection, treating stomach aches, as well as minor respiratory problems and itching of the skin caused by bacteria (Fardin \& Sarina, 2017).

The essential oil compounds in Origanum spp. have been extensively investigated, and its differences between many other species have been reported. The chemical constituents that dominate Origanum vulgare $L$. are monoterpene and sesquiterpene derivatives (Gong et al., 2014). The essential oil from oregano has been shown to have antioxidant, antibacterial, antifungal, diaphoresis, carminative, antispasmodic, analgesic, and antimicrobial activity (De Falco et al., 2013).

Origanum species vary widely, both in their morphological properties and chemical composition. According to the latest taxonomy, there are six subspecies differentiated based on their morphological characteristics: $O$. vulgare $L$. subsp. Glandulosum 
(Desfontaines) letswaart, O. vulgare L. subsp. hirtum (Link) letswaart, O. vulgare L. subsp. Gracile (Koch) letswaart, O. vulgare L. subsp. virens (Hoffmannsegg et Link) letswaart, $O$. vulgare $L$. subsp. vulgare $L$. and $O$. vulgare L. subsp. viride (Boissier) Hayek (Kosakowska \& Czupa, 2018).

When oregano is in its natural form (Figure 1), it has woody stems with aromatic odours that reach $20-30 \mathrm{~cm}$ in height (Lukas et al., 2010). The leaves have oval shapes with broader tips and have a length of $10-44 \mathrm{~mm}$ and a width of $5-25 \mathrm{~mm}$. These leaves are opposite each other on the stem (Force et al., 2000). The edges of the leaves are smooth, and the tips vary in shape ranging from pointed to rounded (Jerkovic et al., 2001). The flowers are clustered in whitish purple bunches with a length of 5-8 $\mathrm{mm}$. Each flower has four stamens with four small seeds on the fruit (Kikuzaki \& Nakatani, 1989). There have been many reports about the benefits of Origanum vulgare $L$. essential oil, but there are no studies that discuss it all. Therefore, the aim of this study was to collect complete and comprehensive information on the benefits of Origanum vulgare $L$. essential oil and its potential to be developed into nanoparticles in dosage forms.

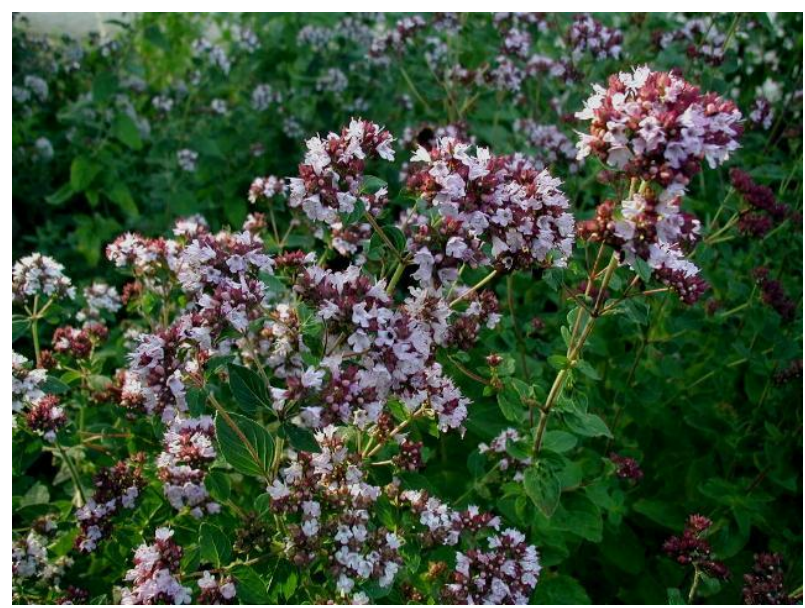

Figure 1: Origanum vulgare L. (Wikipedia, 2020)

\section{Method}

In this paper, a literature study was conducted. The data obtained was in the form of qualitative data and quantitative data. The qualitative data obtained was described in narrative form, and conclusions were drawn from it.

The literature study in the review process of this article was carried out by utilizing online literature sources with the keywords: Origanum vulgare L., oregano, chemical composition, pharmacological activity, and nanotechnology. The primary data sources used were PubMed, Research Gate, ScienceDirect, and Google
Scholar. The inclusion criteria used were published national or international journals; written in Bahasa Indonesian or English. Meanwhile, the exclusion criteria were journals or references that were not valid and that had unclear sources.

\section{Results and discussion}

\section{Chemical compounds of Origanum vulgare $L$.}

The chemical compounds that dominate Origanum vulgare $L$. essential oil are monoterpene and sesquiterpene derivatives (Figure 2). According to research conducted by Gong and the authors, the main chemical compounds within oregano's essential oil are ecitronellol, citronellol acetate, thymol, trans-geraniol, eucalyptol, caryophyllene, eugenol methyl ether, caryophyllene oxide, carvacrol, and germacrene D (Gong et al., 2014).

In the research conducted by De falco and the authors (2013), the chemical compounds present in the oil were influenced by the planting system technique and growth. The oil from the Origanum vulgare L. plants that were grown in single rows was rich in sabinene, while those grown in double rows were richer in ocimenes. Meanwhile, oxygenated monoterpene derivatives were most abundant in terpinen-4-ol compounds (De Falco et al., 2013).

There was a higher content of total sesquiterpene hydrocarbons in fresh plants, with the most highly detected chemical components being $\beta$-caryophyllene, germacrene $D$ and $\alpha$-humulene. Among the oxygenated sesquiterpenes, spathulenol was the most abundant in all the oils and had a greater presence in the dry sample. As for phenolic compounds, carvacrol was the main constituent, and the concentration was higher in dry samples (De Falco et al., 2013).

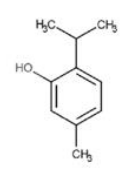

Carvacrol

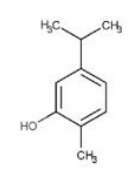

Thymol

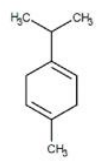

$\gamma$-Terpinene

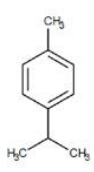

p-Cymene

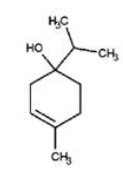

Terpinen-4-ol

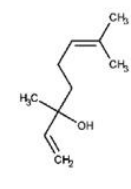

Linalool<smiles>C=CC(=C)CCC=C(C)C</smiles>

$\beta$-Myrcene

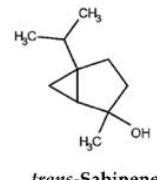
trans-Sabine

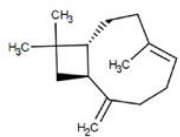

$\beta$-Caryophyllene
Figure 2: Chemical structure of the main compound from Origanum vulgare $L$. (Nayely Leyva-López et al., 2017) 


\section{Pharmacological activity}

\section{Antidiabetic}

In a study conducted by Lemhadri and the authors (2004), an Origanum vulgare $L$. anti-hyperglycemic activity test was carried out in diabetic rats, which were induced with STZ (65 mg/kg intravenous route). Origanum vulgare $L$. extract was administered at a dose of $20 \mathrm{mg} / \mathrm{kg}$ per oral, and its blood glucose-lowering activity was shown (Lemhadri et al., 2004). The antidiabetic effect of oregano extract works using a mechanism that inhibits the production of glucose in the liver or by inducing glucose utilization in peripheral tissues such as the muscle and adipose tissue (Eddouks et al., 2003).

\section{Anxiolytic activity (antianxiety)}

The anxiolytic effect of Origanum vulgare $L$ was determined by carrying out the plus-maze test. In order to determine its sedative and muscle relaxant effect, an open field test and a horizontal wire test were performed. Mice were given oregano extract at doses of 50, 100, and 200 $\mathrm{mg} / \mathrm{kg}$ intraperitoneally and diazepam as standard drugs. The test results proved that the oregano extract had an anxiolytic effect and the potential for minimal sedative effects (Mombeini et al., 2015).

\section{Antioxidant activity}

In a study conducted by Teixeira and the authors (2013), DPPH and FRAP (Ferric reducing antioxidant power) test methods were used to examine the essential oils and extracts from Origanum vulgare $L$. The results showed that both the essential oil and oregano extract had strong antioxidant activity. The strongest antioxidant effects can be affected by the phenolic components of the oregano essential oil and extract (Teixeira et al., 2013).

\section{Antinociceptive activity (analgesic)}

In a study conducted by Khaki and the authors (2013), the antinociceptive effect of Origanum vulgare $L$. extract was tested by providing a dosage range of 1,3 , and $6 \mu \mathrm{g} / \mathrm{rat}$ via intracerebroventricular injection. The test results showed that the oregano extract was able to produce antinociceptive and analgesic effects on the brain. Carvacrol is one of the ingredients of oregano which has an antinociceptive and analgesic effect (Khaki et al., 2013). This study is in accordance with previous studies where oregano extract was administered intraperitoneally and was able to produce analgesic effects when tested with a tail-flick test (Suleyman et al., 1996).

\section{Antiurolytic activity}

The antiurolytic activity of Origanum vulgare L. was proven by in vitro and in vivo tests. The in vitro test used rabbit urinary tracts, and the in vivo test used a mouse model. The in vivo test results showed that a dose of 10$30 \mathrm{mg} / \mathrm{kg}$ oregano extract was able to inhibit the occurrence of polyurea, crystalluria, oxaluria, increase in serum urea and creatinine, thus preventing the formation of crystals in the kidneys when compared to the control group. The inhibitory effect of oxalate crystal formation in the kidneys could also be influenced by the antioxidant activity of the oregano extract (Khan et al., 2011).

\section{Anti-inflammatory activity}

In a study conducted by Javadian and the authors (2016), the anti-inflammatory activity test of methanolic extract of Origanum vulgare $L$. was carried out using inflamed neural cells, namely glial and microglial cells. The test results proved that at a dose of $2.7 \mathrm{mg} / \mathrm{mL}$ of methanolic extract, oregano was able to provide the most optimal anti-inflammatory effect. In addition, at these doses, it also did have cytotoxic effects on normal cells. Thymol, as a component of oregano compounds, caused antiinflammatory effects. The inflammatory barrier mechanism occurred by preventing the secretion of iNOS and TNF- $\alpha$; these are the inflammatory mediators in the microglial cells (Javadian et al., 2016).

\section{Antimelanogenesis}

A study conducted by Liang and the authors (2010) found a new compound resulting from the isolation of the Origanum vulgare $L$. plant called origanoside (1), which is a new phenolic glucoside. Origanoside (1) was tested for its safety and for its antimelanogenesis effect in vitro and in vivo. The test results showed that at a concentration of 0-100 $\mu \mathrm{g} / \mathrm{mL}$, origanoside (1) was not toxic to normal cells. Meanwhile, the in vitro and in vivo test results showed that origanoside (1) was recorded to inhibit tyrosinase activity in cell culture at a dose of $10-20 \mu \mathrm{g} / \mathrm{mL}$ of $16.9-$ $28.6 \%$ (melanoma cells B16). When applied to mouse skin, applying gel containing origanoside (1) for more than ten days showed whitening of skin cells (Liang et al., 2010).

\section{Antifungal activity}

In a study conducted by Adam and the authors (1998), the growth inhibition activity of human pathogens Malassezia furfur, Trichophyton rubrum, and Trichosporon beigelii were tested. Oregano extract with a dilution level of $1 / 50000$ was able to produce better antifungal activity than extracts from Mentha spicata, Lavandula angustifolia, and Salvia fruticosa. Within six hours of exposure, oregano extract was able to inhibit $95 \%$ of active metabolite fungal cells. The components that played the largest role in antifungal activity were carvacrol and thymol (Adam et al., 1998). 


\section{Memory boosting activity}

Abbasnejad and the authors (2006) conducted a study on the effect of Origanum vulgare $L$. induced in male Wistar rats to reduce spatial learning errors. The male Wistar rats were trained in spatial learning tasks by regularly using the T-maze method. The mice that were given oregano extract injections at doses of 150, 300, and $450 \mathrm{mg} / \mathrm{kg}$ were able to show a lower error rate when compared to the normal group. This was observed based on the results of the electrophysiological recordings performed. This pharmacological effect can also be influenced by the effect of antioxidants and anti-acetylcholine esterase compounds such as ursolic acid (Abbasnejad et al., 2006).

\section{Hepatoprotective activity}

Origanum vulgare $L$. extract was tested on male Wistar rats induced by the $\mathrm{CCL}_{4}$-induced hepatotoxicity to see its hepatoprotective ability. The doses of oregano leaf extract given ranged from 50,100, $150 \mathrm{mg} / \mathrm{kg}$ p.o for 15 days. The hepatoprotective effect was best found at a dose of $150 \mathrm{mg} / \mathrm{kg}$ of oregano extract. This was indicated by lower aspartate aminotransferase (AST), alanine aminotransferase (ALT), and alkaline phosphatase (ALP) levels in liver blood serum compared to the normal and negative control groups. Researchers also found lower lipid peroxide levels in test mice (Sikander et al., 2013). In another study, it was shown that the flavonoids and triterpenoids contained by Origanum vulgare L. played an important role in protecting $\mathrm{CCl} 4$-induced liver oxidation (Röhrdanz et al., 2002).

\section{Anti-cancer activity}

In a study conducted by Kubatka and the authors (2017), the anti-tumour effect of Origanum vulgare $L$. was tested in vitro with MCF-7 cells and in vivo on female rats induced by n-nitroso-n-methyl urea. Origanum vulgare $L$. extract was administered orally at a dose of 3 and $30 \mathrm{~g} / \mathrm{kg}$. Based on the results from the in vivo tests, the oregano extract was able to reduce the tumour frequency by $55.5 \%$, the tumour incidence by $44 \%$, and the tumour volume by $44.5 \%$ when compared to the normal group. Meanwhile, the in vitro test results showed that the oregano extract was able to reduce the survival and proliferation rates of MCF-7 cells. In addition, the results of the oregano extract toxicity test showed that no severe side effects were caused, but special attention was needed as there was a slight increase in serum blood glucose levels (Kubatka et al., 2017).

\section{Application of nanoparticle dosage form}

Extracts from plants have natural properties, which means that they are more easily dissolved in oil bases. Meanwhile, active substances in the body will be more easily absorbed if they have a water-soluble form. Pharmaceutical dosage forms with nanotechnology applications such as self-nano emulsifying drug delivery systems (SNEDDS), gold nanoparticles and liposomes can overcome this problem. The small particle sizes with a range of 20-200 $\mathrm{nm}$ can increase the surface area and make it easier for active substances to penetrate the cell membrane towards the target cell in order to increase the effectiveness of the active substance (Chabib et al., 2020).

In a study conducted by Yi Zhao and the authors (2010), a SNEDDS was able to be formulated using the essential oil from Curcuma zedoaria. The resulting particle size had an average value of $68.3 \pm 1.6 \mathrm{~nm}$ and a zeta potential of $-41.2 \pm 1.3 \mathrm{mV}$. Zedoary SNEDDS was stable in storage for up to 12 months, and the drug concentration in the blood was 2.5 times larger than conventional zedoary turmeric oil (Zhao et al., 2010).

In another study conducted by Manconi $M$. and the authors (2018), liposome nanoparticles were able to be formed from thymic essential oil. The characterization results showed that the liposome had a particle size of $89 \mathrm{~nm}$, a zeta potential of $-60 \mathrm{mV}$, and had a small and unilamellar shape. Liposome carriers did not reduce the antioxidant and antimicrobial effects of Thymus capitatus essential oil (Manconi et al., 2018).

Based on both of these data, the essential oils from certain plants have been proven to able to be developed into nanoparticles in dosage forms, and these increase the solubility and stability, which results in pharmacological effects.

\section{Conclusion}

Origanum vulgare $L$. is an excellent medicinal plant that contains many bioactive phytochemicals. The main chemical compound contained in Origanum vulgare $L$. is an essential oil that is rich in monoterpene and sesquiterpene derivatives. In modern scientific literature, Origanum vulgare L. extract has been reported to have potential properties against various diseases as it has antidiabetic, anxiolytic (antianxiety), antioxidant, antinociceptive (analgesic), antiurolytic, anti-inflammatory, antimelanogenesis, antifungal, and anti-cancer activity, as well as the ability to improve memory. The essential oil from Origanum vulgare $L$. has the potential to be developed into nanoparticles in dosage forms. 


\section{References}

Abbasnejad, M., Mirtajadini, M., Afarinesh, M. R., \& Hassibi, N. (2006). Valuation of Origanum vulgare (leaves, stems and flowers) extract on spatial learning in male rats. Physiology and Pharmacology, 10(2), 143-150

Adam, K., Sivropoulou, A., Kokkini, S., Lanaras, T., \& Arsenakis, M. (1998). Antifungal Activities of Origanum vulgare subsp. Hirtum, Mentha spicata, Lavandula angustifolia, and Salvia fruticosa Essential Oils against Human Pathogenic Fungi. Journal of Agricultural and Food Chemistry, 46(5), 1739-1745. https://doi.org/10.1021/jf9708296

Chabib, L., Trianloka, A. M. B., Hidayat, A. M. U. J., Awaluddin, R., \& Firmansyah, F. (2020). Potential Tropical Fruits to Aid Sports Performance and its Prospect to be Developed into Nano supplement. IOP Conference Series: Earth and Environmental Science, 448, 012019. https://doi.org/10.1088/17551315/448/1/012019

De Falco, E., Mancini, E., Roscigno, G., Mignola, E., TaglialatelaScafati, O., \& Senatore, F. (2013). Chemical Composition and Biological Activity of Essential Oils of Origanum vulgare L. subsp. Vulgare L. under Different Growth Conditions. Molecules, 18(12), 14948-14960. https://doi.org/10.3390/molecules181214948

Eddouks, M., Jouad, H., Maghrani, M., Lemhadri, A., \& Burcelin, R. (2003). Inhibition of endogenous glucose production accounts for hypoglycemic effect of Spergularia purpurea in streptozotocin mice. Phytomedicine, 10(6-7), 594-599. https://doi.org/10.1078/094471103322331890

Fardin, F., \& Sarina, S. (2017). The Effect Of Leaf Extract Oregano (Origanum vulgare L.) Bioavailability Of Diazepam Tablets In Mice. The National Journal of Pharmacy, 14(01), 53-58

Force, M., Sparks, W. S., \& Ronzio, R. A. (2000). Inhibition of enteric parasites by emulsified oil of oregano in vivo. Phytotherapy Research, 14(3), 213-214. https://doi.org/10.1002/(SICI)10991573(200005)14:3<213::AID-PTR583>3.0.CO;2-U

Gong, H. Y., Liu, W. H., Lv, G. Y., \& Zhou, X. (2014). Analysis of essential oils of Origanum vulgare from six production areas of China and Pakistan. Revista Brasileira de Farmacognosia, 24(1), 25-32. https://doi.org/10.1590/0102-695X2014241434

Javadian, S., Sabouni, F., \& Haghbeen, K. (2016). Origanum vulgare L. Extracts Versus Thymol: An Anti-Inflammatory Study on Activated Microglial and Mixed Glial Cells: Oregano Antioxidant and Anti-Inflammatory Effects. Journal of Food Biochemistry, 40(1), 100-108. https://doi.org/10.1111/jfbc.12199

Khaki, M. R. A., Pahlavan, Y., Sepehri, G., Sheibani, V., \& Pahlavan, B. (2013). Antinociceptive Effect of Aqueous Extract of Origanum vulgare L. in Male Rats: Possible Involvement of the GABAergic System. 7

Khan, A., Bashir, S., Khan, S. R., \& Gilani, A. H. (2011). Antiurolithic activity of Origanum vulgare is mediated through multiple pathways. BMC Complementary and Alternative Medicine, 11(1), 96. https://doi.org/10.1186/1472-6882-11-96

Kikuzaki, H., \& Nakatani, N. (1989). Structure of a New Antioxidative Phenolic Acid from Oregano ( Origanum vulgare L.). Agricultural and Biological Chemistry, 53(2), 519-524. https://doi.org/10.1080/00021369.1989.10869290

Kosakowska, O., \& Czupa, W. (2018). Morphological and chemical variability of common oregano (Origanum vulgare L. subsp. Vulgare) occurring in eastern Poland. Herba Polonica, 64(1), 1121. https://doi.org/10.2478/hepo-2018-0001
Kubatka, P., Kello, M., Kajo, K., Kruzliak, P., Výbohová, D., Mojžiš, J., Adamkov, M., Fialová, S., Veizerová, L., Zulli, A., Péč, M., Statelová, D., Grančai, D., \& Büsselberg, D. (2017). Oregano demonstrates distinct tumour-suppressive effects in the breast carcinoma model. European Journal of Nutrition, 56(3), 1303-1316. https://doi.org/10.1007/s00394-016-1181-5

Lemhadri, A., Zeggwagh, N.-A., Maghrani, M., Jouad, H., \& Eddouks, M. (2004). Anti-hyperglycaemic activity of the aqueous extract of Origanum vulgare growing wild in Tafilalet region. Journal of Ethnopharmacology, 92(2-3), 251-256. https://doi.org/10.1016/j.jep.2004.02.026

Liang, C.-H., Chou, T.-H., \& Ding, H.-Y. (2010). Inhibition of melanogensis by a novel origanoside from Origanum vulgare. Journal of Dermatological Science, 57(3), 170177.https://doi.org/10.1016/j.jdermsci.2009.12.009

Lukas, B., Schmiderer, C., Mitteregger, U., \& Novak, J. (2010). Arbutin in marjoram and oregano. Food Chemistry, 121(1), 185190. https://doi.org/10.1016/j.foodchem.2009.12.028

Manconi, M., Petretto, G., D'hallewin, G., Escribano, E., Milia, E., Pinna, R., Palmieri, A., Firoznezhad, M., Peris, J. E., Usach, l., Fadda, A. M., Caddeo, C., \& Manca, M. L. (2018). Thymus essential oil extraction, characterization and incorporation in phospholipid vesicles for the antioxidant/antibacterial treatment of oral cavity diseases. Colloids and Surfaces B: Biointerfaces, 171, 115-122. https://doi.org/10.1016/j.colsurfb.2018.07.021

Mombeini, T., Mazloumi, S., \& Shams, J. (2015). Pharmacological Effects of Origanum Vulgare L. in the Elevated Plus-Maze and Open Field Tests in the Rat. 3(2), 9

Nayely Leyva-López, Erick Gutiérrez-Grijalva, Gabriela VazquezOlivo, \& J. Heredia. (2017). Essential Oils of Oregano: Biological Activity beyond Their Antimicrobial Properties. Molecules, 22(6), 989. https://doi.org/10.3390/molecules22060989

Röhrdanz, E., Ohler, S., Tran-Thi, Q.-H., \& Kahl, R. (2002). The Phytoestrogen Daidzein Affects the Antioxidant Enzyme System of Rat Hepatoma H4IIE Cells. The Journal of Nutrition, 132(3), 370375. https://doi.org/10.1093/jn/132.3.370

Sikander, M., Malik, S., Parveen, K., Ahmad, M., Yadav, D., Hafeez, Z. B., \& Bansal, M. (2013). Hepatoprotective effect of Origanum vulgare in Wistar rats against carbon tetrachloride-induced hepatotoxicity. Protoplasma, 250(2), 483-493. https://doi.org/10.1007/s00709-012-0431-5

Suleyman, A., Yusuf, O., Rana, B., \& K. Husnu Can, B. (1996). Investigation of Origanum onites, Sideritis congesta and Satureja cuneifolia Essential Oils for Analgesic Activity. Phytotherapy Research, 10, 342-344. https://doi.org/10.1002/(SICI)10991573(199606)10:4<342::AID-PTR832>3.0.CO;2-W

Teixeira, B., Marques, A., Ramos, C., Serrano, C., Matos, O., Neng, N. R., Nogueira, J. M. F., Saraiva, J. A., \& Nunes, M. L. (2013). Chemical composition and bioactivity of different oregano ( Origanum vulgare ) extracts and essential oil: Composition and bioactivity of oregano products. Journal of the Science of Food and Agriculture, 93(11), 2707-2714. https://doi.org/10.1002/jsfa.6089

Wikipedia. (2020). Oregano [Encyclopedia]. Available at: https://en.wikipedia.org/wiki/Oregano

Zhao, Y., Wang, C., Chow, A. H. L., Ren, K., Gong, T., Zhang, Z., \& Zheng, Y. (2010). Self-nanoemulsifying drug delivery system (SNEDDS) for oral delivery of Zedoary essential oil: Formulation and bioavailability studies. International Journal of Pharmaceutics, 383(1-2), 170-177.https://doi.org/10.1016/j.jpharm.2009.08.035 